\title{
LOW DOSE NITRITE ENHANCES PERFUSION AFTER FLUID RESUSCITATION FROM HEMORRHAGIC SHOCK
}

\author{
Pedro Cabrales \\ La Jolla Bioengineering Institute, La Jolla, CA 92037
}

\begin{abstract}
This study determines the systemic and microvascular hemodynamic consequences of administering a low dose sodium nitrite after fluid resuscitation from hemorrhagic shock. Hemodynamic responses to hemorrhagic shock and resuscitation were studied in the hamster window chamber model. Moderated hemorrhage was induced by arterial controlled bleeding of $50 \%$ of the blood volume (BV) and the hypovolemic state was maintained for one hour. Volume restitution was performed by infusion of $25 \%$ of BV using Hextend ${ }^{\circledR}$ (6\% Hetastarch $670 \mathrm{kDa}$ in lactated electrolyte solution) 10 min after fluid resuscitation $100 \mu \mathrm{l}$ of specific concentrations of sodium nitrite were infused. The experimental groups were named based on the nitrite concentration used, namely: $0 \mu \mathrm{M}, 10 \mu \mathrm{M}$ and $50 \mu \mathrm{M}$. Systemic parameters, microvascular hemodynamics and capillary perfusion (functional capillary density, FCD) were followed during entire protocol. Exogenous $10 \mu \mathrm{M}$ nitrite maintained systemic and microhemodynamic conditions post fluid resuscitation from hemorrhagic shock, compared to $50 \mu \mathrm{M}$ or no nitrite. A moderated increase in plasma nitrite during the early phase of resuscitation reversed arteriolar vasoconstriction and increased capillary perfusion and venous return, improving central cardiac function. Nitrite effects on resistance vessels, directly influenced intravascular pressure redistribution, sustained blood flow, and prevented tissue ischemia. In conclusion, increasing nitrite plasma bioavailability after fluid resuscitation from hemorrhagic shock can be a potential therapy to enhance microvascular perfusion and to improve overall outcome.
\end{abstract}

\section{Keywords}

Microcirculation; hemorrhage; reperfusion; nitric oxide; functional capillary density; perfusion

\section{INTRODUCTION}

Loss of a large intravascular volume of blood results in hemorrhagic shock, a state of hypotension associated with hemodynamic abnormalities that lead to homeostatic imbalance. 1,2 In the microcirculation, hypovolemia induces capillary collapse due the decrease in mean arterial pressure (MAP) and when cardiac output is accompanied by a significant decrease of

(C) 2009 Elsevier Ireland Ltd. All rights reserved.

Correspondence to: Pedro Cabrales, Ph.D., La Jolla Bioengineering Institute, 505 Coast Boulevard South Suite \#405, La Jolla, CA 92037 , Telephone: (858) 534-2315, pcabrales@ucsd.edu .

Conflict of interest statement,

All authors do not have any financial or personal relationships with other people or organizations that could inappropriately influence (bias) in their work.

Publisher's Disclaimer: This is a PDF file of an unedited manuscript that has been accepted for publication. As a service to our customers we are providing this early version of the manuscript. The manuscript will undergo copyediting, typesetting, and review of the resulting proof before it is published in its final citable form. Please note that during the production process errors may be discovered which could affect the content, and all legal disclaimers that apply to the journal pertain. 
functional capillary density (FCD), perfusion and tissue $\mathrm{PO}_{2} \cdot{ }^{3-5}$ One of the hypotheses to explain the hemorrhage-induced collapse is that the endothelium shear stress dependant nitric oxide (NO) synthase (NOS) is significantly impaired, because of the reduced hematocrit (blood viscosity) and blood flow. ${ }^{4}$ In such pathophysiological situations, the metabolic demand of the tissues could give the signal to vasodilate, although, from a mechanistic viewpoint, a NOS pathway is not optimal, since tissues are hypoxic and oxygen is a co-substrate for NO production. In this respect, a NOS-independent pathway, especially nitrite reduction to NO seems a more suitable and simple strategy to reverse hemorrhage-induced vasoconstriction.

The aim of the present study was to investigate whether, nitrite in physiologically relevant concentrations; upon reaching a physiologically acidic milieu post hemorrhagic shock, would act as a vasodilator, thus increasing microvascular perfusion during fluid resuscitation from hemorrhagic shock. To achieve this objective, our experimental hamster model was subjected to a hemorrhage of $50 \%$ of blood volume (BV), followed by one hour hypovolemic shock. The resuscitation was implemented in two steps, the initial phase was $25 \%$ of BV of fluid resuscitation and, ten minutes after, a small volume $(100 \mu \mathrm{l})$ of sodium nitrite was provided. The fluid resuscitation was implemented with Hextend ${ }^{\circ}$ (Hospira; Lake Forest, IL, 6\% Hetastarch $670 \mathrm{kDa}$ in Lactated Electrolyte Injection). Animals were divided in different groups based on the concentration of nitrite infused, $0 \mu \mathrm{M}, 10 \mu \mathrm{M}$ and $50 \mu \mathrm{M}$. Systemic and microvascular parameters were studied up to $90 \mathrm{~min}$ after resuscitation.

\section{METHODS}

\section{Animal Preparation}

Investigations were performed in 55 - 65 g male Golden Syrian Hamsters (Charles River Laboratories, Boston, MA) fitted with a dorsal skinfold window chamber. Animal handling and care followed the NIH Guide for the Care and Use of Laboratory Animals. The experimental protocol was approved by the local animal care committee. The hamster window chamber model is widely used for microvascular studies in the unanesthetized state, and the complete surgical technique is described in detail elsewhere. ${ }^{6,7}$ Animals were anesthetized again, and arterial and vein catheters filled with a heparinized saline solution $(30 \mathrm{IU} / \mathrm{ml})$ were implanted. The microvasculature was examined 3 to 4 days after the initial surgery and only animals with window chambers whose tissue did not present regions of low perfusion, inflammation, and edema were entered into the study. ${ }^{8}$

\section{Inclusion Criteria}

Animals were suitable for the experiments if: 1) systemic parameters were within normal range, namely, heart rate $(\mathrm{HR})>340 \mathrm{beat} / \mathrm{min}$, mean arterial blood pressure (MAP) $>80 \mathrm{mmHg}$, systemic $\mathrm{Hct}>45 \%$, and arterial oxygen partial pressure $\left(\mathrm{PaO}_{2}\right)>50 \mathrm{mmHg}$; and 2) microscopic examination of the tissue in the chamber observed under a x650 magnification did not reveal signs of edema or bleeding.

\section{Acute hemorrhage resuscitation protocol}

Acute hemorrhage was induced by withdrawing $50 \%$ of estimated total blood volume (BV) via the carotid artery catheter within $5 \mathrm{~min}$. Total BV was estimated as $7 \%$ of body weight. One hour after hemorrhage induction, animals were received $25 \%$ of BV of fluid resuscitation (200 $\mu \mathrm{l} / \mathrm{min}$ ) jugular venin catheter, implemented with Hextend® (Hospira; Lake Forest, IL, $6 \%$ Hetastarch $670 \mathrm{kDa}$ in Lactated Electrolyte Injection). Ten minutes after fluid resuscitation, a small volume $100 \mu \mathrm{l}$ of sodium nitrite solution in normal saline was infused via carotid artery catheter. Animals were divided in different groups, based on the concentration of nitrite infused, $0 \mu \mathrm{M}, 10 \mu \mathrm{M}$ and $50 \mu \mathrm{M}$. Systemic and microvascular parameters were analyzed 
before hemorrhage (baseline), after hemorrhage (shock), and up to 90 min after volume replacement (resuscitation).

\section{Experimental groups}

Animals were randomly divided into three experimental groups after fluid resuscitation, and received a specific concentration of sodium nitrite infused: 1) $\boldsymbol{0} \boldsymbol{\mu} \boldsymbol{M}$, no nitrite only the vehicle; 2) $10 \mu M, 10 \mu \mathrm{M}$ of sodium nitrite (Sigma, St Louis, Mo, USA); 3) $50 \mu M, 50 \mu \mathrm{M}$ of sodium nitrite. Absolute nitrite dose per animal were 0,1 and 5 ๆmoles, respectively. Eighteen animals were entered into the study, they were randomly assigned to the following experimental groups: $\boldsymbol{0} \boldsymbol{\mu M}(\mathrm{n}=6) ; \mathbf{1 0} \boldsymbol{\mu} \boldsymbol{M}(\mathrm{n}=6)$; and $\mathbf{5 0} \boldsymbol{\mu} \boldsymbol{M}(\mathrm{n}=6)$. Systemic data for baseline and shock were obtained by combining all experimental groups.

\section{Systemic Parameters}

MAP and heart rate (HR) were recorded continuously (MP 150, Biopac System; Santa Barbara, CA). Hct was measured from centrifuged arterial blood samples taken in heparinized capillary tubes. $\mathrm{Hb}$ content was determined spectrophotometrically from a single drop of blood (BHemoglobin, Hemocue, Stockholm, Sweden). Blood samples for viscosity and colloid osmotic pressure measurements were quickly withdrawn from the animal into a heparinized syringe at the end of the experiment. Viscosity was measured in a DV-II plus (Brookfield Engineering Laboratories, Middleboro, MA) at a shear rate of $160 / \mathrm{sec}$. Colloid osmotic pressure was measured using a 4420 Colloid Osmometer (Wescor, Logan, UT).

\section{Blood Chemistry and Biophysical Properties}

Arterial blood was collected in heparinized glass capillaries $(0.05 \mathrm{ml})$ and immediately analyzed for $\mathrm{PaO}_{2}, \mathrm{PaCO}_{2}$, base excess (BE) and $\mathrm{pH}$ (Blood Chemistry Analyzer 248, Bayer, Norwood, MA). The comparatively low $\mathrm{PaO}_{2}$ and high $\mathrm{PaCO}_{2}$ of these animals are a consequence of their adaptation to a fossorial environment. However, microvascular $\mathrm{PO}_{2}$ distribution in the chamber window model is the same as in other rodents such as mice. ${ }^{2}$

\section{Methemoglobin (MetHb) measurement}

Blood is collected into microhematocrit tubes and MetHb determination was established according to Winterbourn. ${ }^{10}$ Calibration is ensured using standard levels at 5.2\%, 2.6\% and 1.2\% MetHb (RNA Medical, Bayer Diagnostics Medfield, MA).

\section{Plasma nitrite}

Blood samples were collected from carotid artery, and centrifuged to separate RBCs and plasma. Plasma proteins were removed by adding equivolume of methanol, and centrifuged at $15000 \mathrm{rpm}$ for $10 \mathrm{~min}$. Concentrations of NOx in the supernatant were measured with a NOx analyzer (ENO-20; Eicom, Kyoto, Japan). This analyzer combines Griess method and highperformance liquid chromatography.

\section{Microvascular Experimental Setup}

The unanesthetized animal was placed in a restraining tube with a longitudinal slit from which the window chamber protruded, then fixed to the microscopic stage of a transillumination intravital microscope (BX51WI, Olympus, New Hyde Park, NY). The animals were given 20 min to adjust to the change in the tube environment before measurements. The tissue image was projected onto a charge-coupled device camera (COHU 4815) connected to a videocassette recorder and viewed on a monitor. Measurements were carried out using a 40X (LUMPFLWIR, numerical aperture 0.8 , Olympus) water immersion objective. The same sites of study 
were followed throughout the experiment so comparisons could be made directly to baseline levels.

\section{Functional Capillary Density (FCD)}

Functional capillaries, defined as those capillary segments that have RBC transit of at least one $\mathrm{RBC}$ in a 60s period in 10 successive microscopic fields were assessed, totaling a region of $0.46 \mathrm{~mm}^{2}$. Each field had between two and five capillary segments with RBC flow. FCD $\left(\mathrm{cm}^{-1}\right)$, i.e., total length of RBC perfused capillaries divided by the area of the microscopic field of view, was evaluated by measuring and adding the length of capillaries that had RBC transit in the field of view. ${ }^{11,12}$

\section{Microhemodynamics}

Arteriolar and venular blood flow velocities were measured online by using the photodiode cross-correlation method ${ }^{13}$ (Photo Diode/Velocity Tracker Model 102B, Vista Electronics, San Diego, CA). The measured centerline velocity (V) was corrected according to vessel size to obtain the mean $\mathrm{RBC}$ velocity. ${ }^{14} \mathrm{~A}$ video image-shearing method was used to measure vessel diameter (D). ${ }^{15}$ Blood flow $(\mathrm{Q})$ was calculated from the measured values as $\mathrm{Q}=\pi \times \mathrm{V}$ (D/ $2)^{2}$. Changes in arteriolar and venular diameter from baseline were used as indicators of a change in vascular tone. This calculation assumes a parabolic velocity profile and has been found to be applicable to tubes of $15-80 \mu \mathrm{m}$ internal diameters and for Hcts in the range of 6 $-60 \% .^{14}$

\section{Data analysis}

Results are presented as mean \pm standard deviation. Data within each group were analyzed using analysis of variance for repeated measurements (ANOVA, Kruskal-Wallis test). When appropriate, post hoc analyses were performed with the Dunns multiple comparison test. Microhemodynamic measurements were compared to baseline levels obtained before the experimental procedure. All statistics were calculated using GraphPad Prism 4.01 (GraphPad Software, Inc., San Diego, CA). Changes were considered statistically significant if $\mathrm{P}<0.05$.

\section{RESULTS}

\section{Systemic response to hemorrhage resuscitation}

Systemic hemodynamic and blood parameters are presented in detail on Table 1. All animals tolerated the entire hemorrhage shock resuscitation protocol without visible signs of discomfort. Hemorrhage and shock reduced $\mathrm{Hct}$ and $\mathrm{Hb}$ from baseline. Fluid resuscitation decreased $\mathrm{Hct}$ and $\mathrm{Hb}$ further from baseline. Prolonged volume expansion of the colloid was observed between 60 and 90 min after of resuscitation. No changes in Hct or Hb were introduced by the nitrite. Fluid resuscitation followed by $10 \mu \mathrm{M}$ or $50 \mu \mathrm{M}$ nitrite produced an increase in MetHb at 60 and 90 min after resuscitation. Whole blood and plasma viscosity, and plasma COP were statistically reduced for all groups (compared to baseline blood viscosity). Baseline rheological properties and COP were obtained from the blood of hamsters that did not undergo the shock protocol.

Hemorrhagic shock decreased arterial $\mathrm{pH}$ and $\mathrm{pCO}_{2}$, significantly compromising acid based balance relative to baseline. Resuscitation partially recovered all blood gas parameters. Arterial $\mathrm{pO}_{2}$ remained higher than baseline for all groups during shock and resuscitation. $60 \mathrm{~min}$ after resuscitation $\mathrm{pCO}_{2}, \mathrm{pH}$ was significantly lower for $0 \mu \mathrm{M}$ and $50 \mu \mathrm{M}$ nitrite compare to baseline, and $90 \mathrm{~min}$ after resuscitation, only animals not treated with nitrite after resuscitation remained different from baseline. Plasma nitrite $90 \mathrm{~min}$ after resuscitation was different from baseline for all the groups, however not different among groups. 
Hemorrhage and shock decreased MAP from baseline $(\mathrm{P}<0.05)$. Changes in MAP during the hemorrhagic shock resuscitation protocol for all experimental groups are presented in Figure 1. Fluid resuscitation partially restored MAP from the shock in all groups. Blood pressure was significantly lower than baseline at all time points. No differences between groups were observed prior to nitrite treatment. Infusion of $50 \mu \mathrm{M}$ of nitrite decreased MAP compared to $0 \mu \mathrm{M}$ and remained lower during the observation time. Infusion $10 \mu \mathrm{M}$ of nitrite had a significantly lower effect in MAP than $50 \mu \mathrm{M}$ during the first hour, although no difference was observed $90 \mathrm{~min}$ after resuscitation. Heart rate during shock was not different during shock and after fluid resuscitation for all groups compared to baseline. Infusion of $50 \mu \mathrm{M}$ of nitrite produced an increase in heart rate compared to $0 \mu \mathrm{M}$. Differences in heart rate between groups disappeared within the initial $60 \mathrm{~min}$ after resuscitation.

\section{Microvascular responses to hemorrhage resuscitation}

Microvascular arteriolar diameter and blood flow are presented in Figure 2. Arterioles were significantly constricted from baseline during hemorrhagic shock. Nitrite infusion, $10 \mu \mathrm{M}$ and $50 \mu \mathrm{M}$, restored arterial vascular tone and produced arteriolar vasodilation, respectively. Arteriolar tone differences remained significant up to $60 \mathrm{~min}$ after resuscitation, and $90 \mathrm{~min}$ after resuscitation, arteriole diameters for all groups were not different among groups.

Microvascular flow was significantly decreased from baseline after hemorrhage and during shock. Microvascular flow was increased, proportional to the concentration of nitrite infused, during the initial $30 \mathrm{~min}$ after resuscitation. Blood flows were not different for all groups, 90 min after resuscitation. Changes in the number of capillary perfused with RBCs during the protocol are presented in Figure 3. FCD was significantly reduced after hemorrhage and shock. Resuscitation partially restored FCD in all groups. Statistical changes in FCD were observed after $10 \mu \mathrm{M}$ nitrite, post nitrite infusion and after 60 and 90 min compared to other groups, respectively.

Calculated vascular resistance (MAP normalized microvascular flow) is presented in Figure 4. Peripheral vascular resistance increased after hemorrhagic shock (2.3 times the resistance at baseline), and decreased after fluid resuscitation (1.6 times the resistance at baseline). Nitrite infusion decreased vascular resistance proportional to the concentration, and these changes remained over the entire observation time. $50 \mu \mathrm{M}$ nitrite decreased vascular resistance to baseline level.

\section{DISCUSSION}

The principal finding of the study is that appropriated fluid resuscitation from hemorrhagic shock can be complemented with a low concentration of nitrite to obtain a superior systemic and microvascular hemodynamic condition. The importance of exogenous nitrite, during anemic, hypoxic, and hypovolemic conditions is mostly evidenced by the resulting decrease in vascular resistance and an increase in perivascular perfusion. Restoration of blood pressure with incomplete recovery of perfusion after resuscitation prevents the reversal of the microvascular collapse. Low dose nitrite supplementation after fluid resuscitation improves microvascular perfusion through peripheral vasodilatation, without decreasing blood pressure.

Several mechanisms for the nitrite-mediated vasodilation during hypoxia have been proposed, these are essentially based on non-enzymatic or enzymatic reduction of nitrite to NO, both facilitated by acidic conditions. ${ }^{16}$ A pure $\mathrm{pH}$-dependent non-enzymatic nitrite reduction to NO has been reported for the gastric lumen, however, such strongly acidic conditions never occur during ischemic/hypoxic tissues. ${ }^{17}$ The one electron reduction to convert nitrite into NO can be catalyzed by heme-containing molecules (xanthine oxidase, cytochrome P-450, hemoglobin, myoglobin and neuroglobin) and further enhanced by local acidic $\mathrm{pH} .{ }^{18-20}$ Our 
data from previously published study, indicates that normal hamster window tissue $\mathrm{pH}$ is 7.24 , and that $10 \mathrm{~min}$ after resuscitation with hydroxyethyl starch (same protocol and solution used in this study), it decreases to $6.90 .{ }^{9}$ The present study demonstrates that when the surrounding tissue $\mathrm{pH}$ is reduced, a small dose of nitrite induces a pronounced microvascular vasodilation. In view of the close chemical connection between nitrite and NO, it is tempting to assume that nitrite acts as a source of NO when functioning as a vasodilator. Independently of the mechanism of production of NO from nitrite, the supplementation of nitrite after resuscitation induced vasodilation, decreased blood pressure, increased perfusion and decreased vascular resistance.

Clinical application of fluid resuscitation, in combination with vasoactive support, can be effective restoring the microcirculation, although its effect on the microcirculation cannot be concluded based on the measurement of systemic variables alone. Orthogonal polarization spectral (OPS) imaging, and side-stream dark-field imaging were recently developed for noninvasive visualization of the microcirculation in tissues protected by a thin epithelial layer on humans. ${ }^{21,22}$ Recent clinical studies have demonstrated the coexistence of microcirculatory and macrocirculatory alterations, and that microvascular blood flow alterations influence systemic factors ${ }^{23}$, similar to the experimental result presented in the current manuscript. Study of patients with severe sepsis and septic shock, on the sublingual microcirculation using the OPS technique, presented severe microcirculatory dysfunction and hypoperfusion, and did not correlate to arterial pressure or cardiac index. ${ }^{24,25}$ Additionally, these investigations presented that the local microvascular alterations observed, were reversible by topical application of a high dose of acetylcholine, explaining why vasodilators may be of value to treat shock. ${ }^{24}$ Vasodilator therapy by administration of nitroglycerin with adequate volume support, reinstated capillary flow and restored sublingual microcirculation; unfortunately, it also induced a marked hypotension. ${ }^{26}$

Exogenous nitrite has the ability to increase perfusion when administered after fluid resuscitation from hemorrhagic shock, making it a promising therapeutic agent. ${ }^{27,28} \mathrm{In}$ conditions of low oxygen and $\mathrm{pH}$, vasodilator effects, derived from nitrite supplementation, suggest broader therapeutic application for nitrite, compared to other NO donors. Nitroglycerin is an organic nitrate, and the NO released undoubtedly involves specific enzymes and reducing agents. ${ }^{29,30}$ In other donors, the NO is bound to a nucleophile adduct, that spontaneous decomposes liberating $\mathrm{NO}$ at physiological $\mathrm{pH}$ and temperature. ${ }^{31}$ The premature release of $\mathrm{NO}$ is prevented by preparation and dilution in alkaline solutions. NO release by nitroglycerin and NO donors is not determined by the local conditions, resulting in harmful or ineffective NO levels, as their optimal dose is difficult to determine. Nitrite, on the other hand, acts as a stable endocrine pool of NO that is selectively reduced to NO, through heme-mediated reduction in ischemic conditions, and has different limitations. In the current study, nitrite infusion's only minor, negative side effect was the formation of metHb, which can potentially decrease oxygenation. Mild methemoglobinemia was untreated in the study, although If treatment is needed methylene blue is an effective antidote ( 1 to $2 \mathrm{mg} / \mathrm{kg}$ ) infused intravenously. Methylene blue reduces MetHb levels by acting as a cofactor to increase the activity of NADPH-metHb reductase. ${ }^{1}$ Notably, after the discovery of NO as an important regulator of vascular tone, the role of $\mathrm{NO}$ and $\mathrm{NO}$ adducts (e.g. nitrite) during shock, was assumed to be negative, and NOS inhibitors were evaluated to prevent, revert, or at least minimize hypotension induced during shock, with negative outcome. ${ }^{32,33}$

In summary, current findings suggest that nitrite infusion post fluid resuscitation reverted arteriolar constriction, decreased blood pressure, and peripheral vascular resistance. Nitrite's effect on resistance vessels directly influences pressure redistribution in the circulation, sustaining blood flow and preventing tissue ischemia. Furthermore, results show that the principal factor in ensuring hemodynamic restoration by nitrite is not related to a volume effect, 
since Hcts were not different between groups. Based on previous studies during hypovolemic shock, microvascular dysfunctions observed in the hamster window model reflect the conditions of major organs, due to its anatomical location and circulatory regulation mechanism. ${ }^{34}$ Even after successful volume restoration, a de-compensatory phase is characterized by an inability to maintain blood pressure and restore microvascular perfusion. Low dose nitrite supplementation after fluid resuscitation relaxes blood vessels and improves microvascular conditions. The major limitation for the therapeutic use of nitrite, is a potential contributor to MetHb levels by reacting rapidly with $\mathrm{OxyHb}$, which could potentially hinder oxygen transport.

\section{Supplementary Material}

Refer to Web version on PubMed Central for supplementary material.

\section{Acknowledgments}

This work was supported by Bioengineering Research Partnership grant R24-HL64395 and grants R01-HL62354, R01-HL62318 and R01-HL76182. The authors thank Froilan P. Barra and Cynthia Walser for the surgical preparation of the animals.

\section{REFERENCES}

1. Cabrales P, Intaglietta M, Tsai AG. Transfusion restores blood viscosity and reinstates microvascular conditions from hemorrhagic shock independent of oxygen carrying capacity. Resuscitation 2007;75:124-34. [PubMed: 17481796]

2. Cabrales P, Tsai AG, Intaglietta M. Exogenous nitric oxide induces protection during hemorrhagic shock. Resuscitation. 2009

3. Tsai AG, Intaglietta M. The unusual properties of effective blood substitutes. Keio J Med 2002;51:1720. [PubMed: 11951374]

4. Salazar Vazquez BY, Wettstein R, Cabrales P, et al. Microvascular experimental evidence on the relative significance of restoring oxygen carrying capacity vs. blood viscosity in shock resuscitation. Biochim Biophys Acta 2008;1784:1421-7. [PubMed: 18502215]

5. Lundvall J, Gustafsson D. Impairment during marked hypotension of the plasma volume control in hemorrhage. Acta Physiol Scand 1982;114:371-8. [PubMed: 7136768]

6. Colantuoni A, Bertuglia S, Intaglietta M. Quantitation of rhythmic diameter changes in arterial microcirculation. Am J Physiol 1984;246:H508-H17. [PubMed: 6720909]

7. Endrich B, Asaishi K, Götz A, Messmer K. Technical report: A new chamber technique for microvascular studies in unanaesthetized hamsters. Res Exp Med 1980;177:125-34.

8. Tsai AG, Friesenecker B, McCarthy M, et al. Plasma viscosity regulates capillary perfusion during extreme hemodilution in hamster skin fold model. Am J Physiol 1998;275:H2170-H80. [PubMed: 9843817]

9. Cabrales P, Tsai AG, Frangos JA, Intaglietta M. Role of endothelial nitric oxide in microvascular oxygen delivery and consumption. Free Radic Biol Med 2005;39:1229-37. [PubMed: 16214038]

10. Winterbourn, CC. CRC Handbook of Methods for Oxygen Radical Research. 1th ed.. CRC Press; Boca Raton, Florida: 1985. Reaction of superoxide with hemoglobin; p. 137-41.

11. Cabrales P, Tsai AG, Intaglietta M. Microvascular pressure and functional capillary density in extreme hemodilution with low and high plasma viscosity expanders. Am J Physiol 2004;287:H363-H73.

12. Tsai AG, Cabrales P, Winslow RM, Intaglietta M. Microvascular oxygen distribution in awake hamster window chamber model during hyperoxia. Am J Physiol Heart Circ Physiol 2003;285:H1537-H45. [PubMed: 12805029]

13. Intaglietta M, Silverman NR, Tompkins WR. Capillary flow velocity measurements in vivo and in situ by television methods. Microvasc Res 1975;10:165-79. [PubMed: 1186524]

14. Lipowsky HH, Zweifach BW. Application of the "two-slit" photometric technique to the measurement of microvascular volumetric flow rates. Microvasc Res 1978;15:93-101. [PubMed: 634160] 
15. Intaglietta M, Tompkins WR. Microvascular measurements by video image shearing and splitting. Microvasc Res 1973;5:309-12. [PubMed: 4709728]

16. Lundberg JO, Weitzberg E. NO generation from nitrite and its role in vascular control. Arterioscler Thromb Vasc Biol 2005;25:915-22. [PubMed: 15746440]

17. Kugler P, Drenckhahn D. Intrinsic source of stomach NO. Nature 1994;370:25-6. [PubMed: 8015600]

18. Cosby K, Partovi KS, Crawford JH, et al. Nitrite reduction to nitric oxide by deoxyhemoglobin vasodilates the human circulation. Nat Med 2003;9:1498-505. [PubMed: 14595407]

19. Kozlov AV, Staniek K, Nohl H. Nitrite reductase activity is a novel function of mammalian mitochondria. FEBS Lett 1999;454:127-30. [PubMed: 10413109]

20. Zhang Z, Naughton DP, Blake DR, et al. Human xanthine oxidase converts nitrite ions into nitric oxide (NO). Biochem Soc Trans 1997;25:524S. [PubMed: 9388740]

21. Groner W, Winkelman JW, Harris AG, et al. Orthogonal polarization spectral imaging: a new method for study of the microcirculation. Nat Med 1999;5:1209-12. [PubMed: 10502828]

22. Slaaf DW, Tangelder GJ, Reneman RS, et al. A versatile incident illuminator for intravital microscopy. Int J Microcirc Clin Exp 1987;6:391-7. [PubMed: 3429145]

23. Ince C. The microcirculation is the motor of sepsis. Crit Care 2005;9(Suppl 4):S13-9. [PubMed: 16168069]

24. De Backer D, Creteur J, Preiser JC, et al. Microvascular blood flow is altered in patients with sepsis. Am J Respir Crit Care Med 2002;166:98-104. [PubMed: 12091178]

25. De Backer D, Creteur J, Dubois MJ, et al. Microvascular alterations in patients with acute severe heart failure and cardiogenic shock. Am Heart J 2004;147:91-9. [PubMed: 14691425]

26. Spronk PE, Ince C, Gardien MJ, et al. Nitroglycerin in septic shock after intravascular volume resuscitation. Lancet 2002;360:1395-6. [PubMed: 12423989]

27. Dejam A, Hunter CJ, Tremonti C, et al. Nitrite infusion in humans and nonhuman primates: endocrine effects, pharmacokinetics, and tolerance formation. Circulation 2007;116:1821-31. [PubMed: 17893272]

28. Lundberg JO, Weitzberg E, Gladwin MT. The nitrate-nitrite-nitric oxide pathway in physiology and therapeutics. Nat Rev Drug Discov 2008;7:156-67. [PubMed: 18167491]

29. Bennett BM, McDonald BJ, Nigam R, Simon WC. Biotransformation of organic nitrates and vascular smooth muscle cell function. Trends Pharmacol Sci 1994;15:245-9. [PubMed: 7940987]

30. McGuire JJ, Anderson DJ, Bennett BM. Inhibition of the biotransformation and pharmacological actions of glyceryl trinitrate by the flavoprotein inhibitor, diphenyleneiodonium sulfate. J Pharmacol Exp Ther 1994;271:708-14. [PubMed: 7965786]

31. Maragos CM, Morley D, Wink DA, et al. Complexes of .NO with nucleophiles as agents for the controlled biological release of nitric oxide. Vasorelaxant effects. J Med Chem 1991;34:3242-7. [PubMed: 1956043]

32. Md S, Moochhala SM, Siew-Yang KL. The role of inducible nitric oxide synthase inhibitor on the arteriolar hyporesponsiveness in hemorrhagic-shocked rats. Life Sci 2003;73:1825-34. [PubMed: 12888121]

33. Thiemermann C, Szabo C, Mitchell JA, Vane JR. Vascular hyporeactivity to vasoconstrictor agents and hemodynamic decompensation in hemorrhagic shock is mediated by nitric oxide. Proc Natl Acad Sci U S A 1993;90:267-71. [PubMed: 7678341]

34. Cabrales P, Tsai AG, Intaglietta M. Is resuscitation from hemorrhagic shock limited by blood oxygencarrying capacity or blood viscosity? Shock 2007;27:380-9. [PubMed: 17414420] 

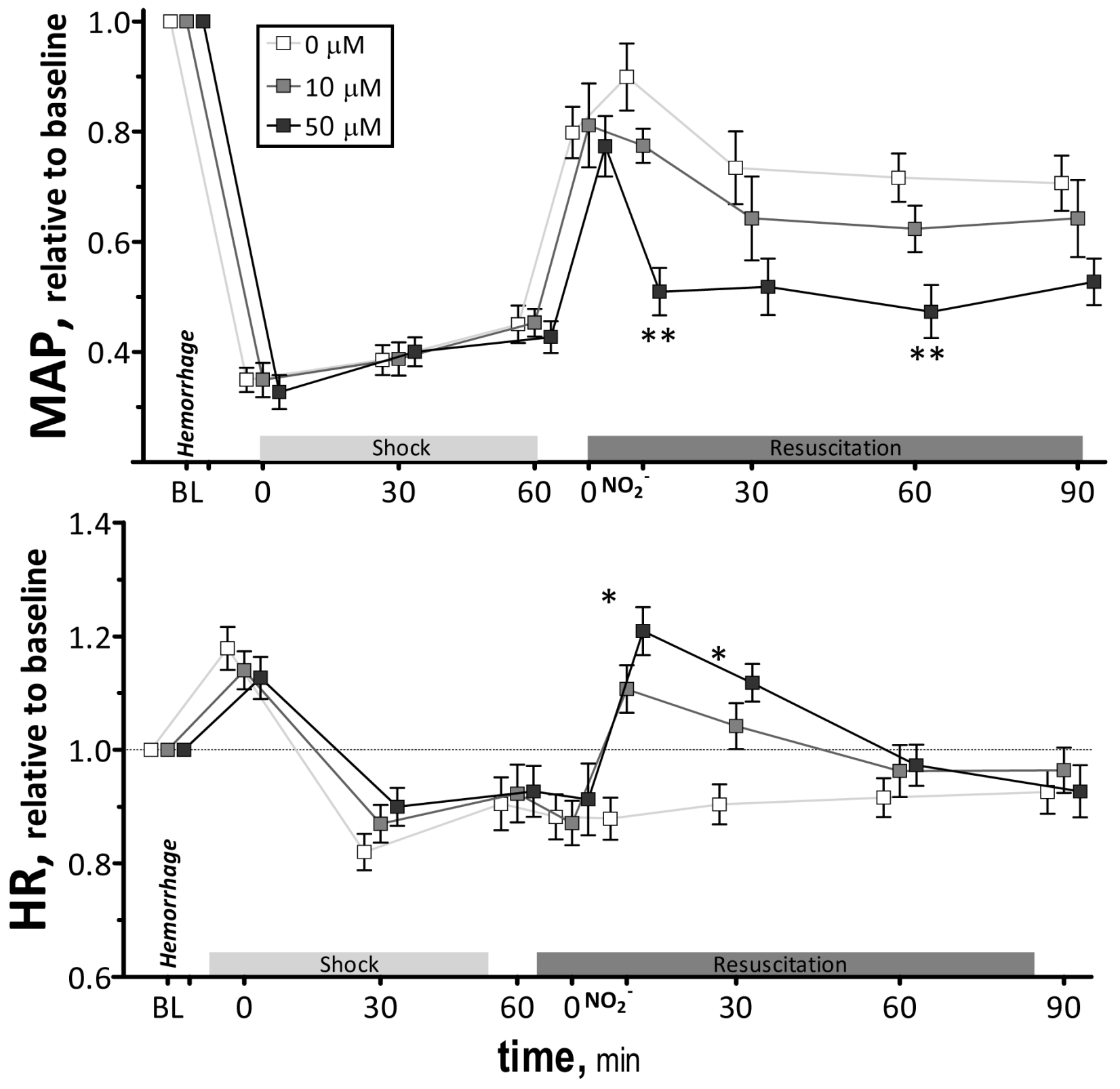

Figure 1.

Relative changes in mean arterial pressure (MAP) and heart rate (HR) during hemorrhagic shock resuscitation for all groups. Mean arterial pressure $(\mathrm{mmHg}$, mean $\pm \mathrm{SD})$ in each animal group were as follows: Baseline: $0 \mu \mathrm{M}(106 \pm 9, \mathrm{n}=6) ; 10 \mu \mathrm{M}(\mathrm{A}: 109 \pm 8, \mathrm{n}=6) ; 50 \mu \mathrm{M}(\mathrm{A}$ : $107 \pm 9, \mathrm{n}=6$ ). Heart rate (bpm, mean $\pm \mathrm{SD}$ ) in each animal group were as follows: Baseline: $0 \mu \mathrm{M}(436 \pm 26, \mathrm{n}=6) ; 10 \mu \mathrm{M}(\mathrm{A}: 429 \pm 25, \mathrm{n}=6) ; 50 \mu \mathrm{M}(\mathrm{A}: 447 \pm 29, \mathrm{n}=6) . \mathrm{n}=$ number of vessels studied. Broken line represents baseline level. **, $\mathrm{P}<0.05,50 \mu \mathrm{M}$ compared to $0 \mu \mathrm{M}$ and $10 \mu \mathrm{M} ; *, \mathrm{P}<0.05,50 \mu \mathrm{M}$ compared to $0 \mu \mathrm{M}$. 

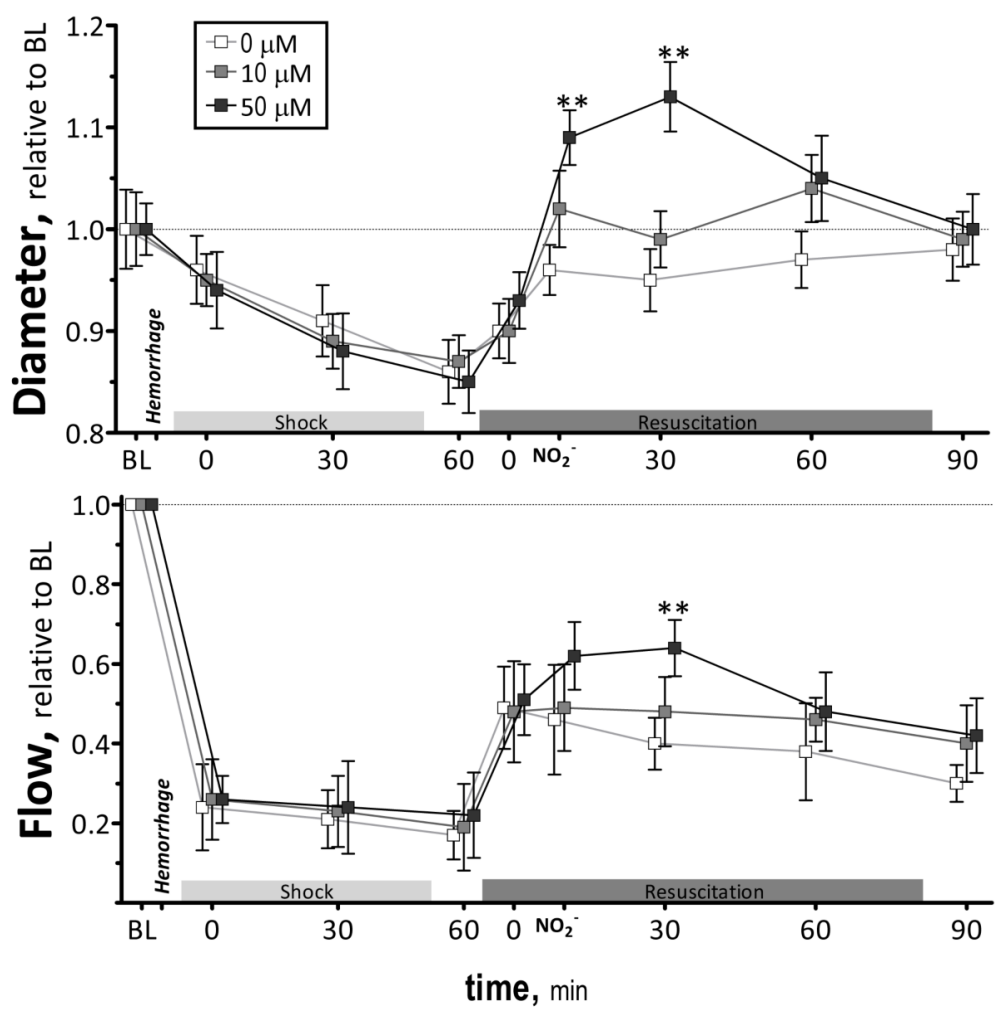

Figure 2.

Relative changes in arteriolar diameter and blood flow during the hemorrhagic shock resuscitation for all groups. Diameters $(\mu \mathrm{m}$, mean $\pm \mathrm{SD})$ in each animal group were as follows: Baseline: $0 \mu \mathrm{M}$ (arterioles (A): $61 \pm 9, \mathrm{n}=44) ; 10 \mu \mathrm{M}$ (A: $60 \pm 8, \mathrm{n}=45$ ); $50 \mu \mathrm{M}$ (A: $63 \pm 9, \mathrm{n}$ $=44) . \mathrm{n}=$ number of vessels studied. $\mathrm{RBC}$ velocities $(\mathrm{mm} / \mathrm{s}$, mean $\pm \mathrm{SD})$ for each animal group were as follows: Baseline: $0 \mu \mathrm{M}(\mathrm{A}: 4.5 \pm 0.9) ; 10 \mu \mathrm{M}(\mathrm{A}: 4.4 \pm 0.8) ; 50 \mu \mathrm{M}(\mathrm{A}: 4.4 \pm 0.7)$.

Calculated flows (nl/s, mean \pm SD) were as follows: Baseline: $0 \mu \mathrm{M}(\mathrm{A}: 13 \pm 4) ; 10 \mu \mathrm{M}(\mathrm{A}: 12$ \pm 3 ); $50 \mu \mathrm{M}(\mathrm{A}: 12 \pm 4)$. Broken line represents baseline level. **, $\mathrm{P}<0.05,50 \mu \mathrm{M}$ compared to $0 \mu \mathrm{M}$ and $10 \mu \mathrm{M}$. 


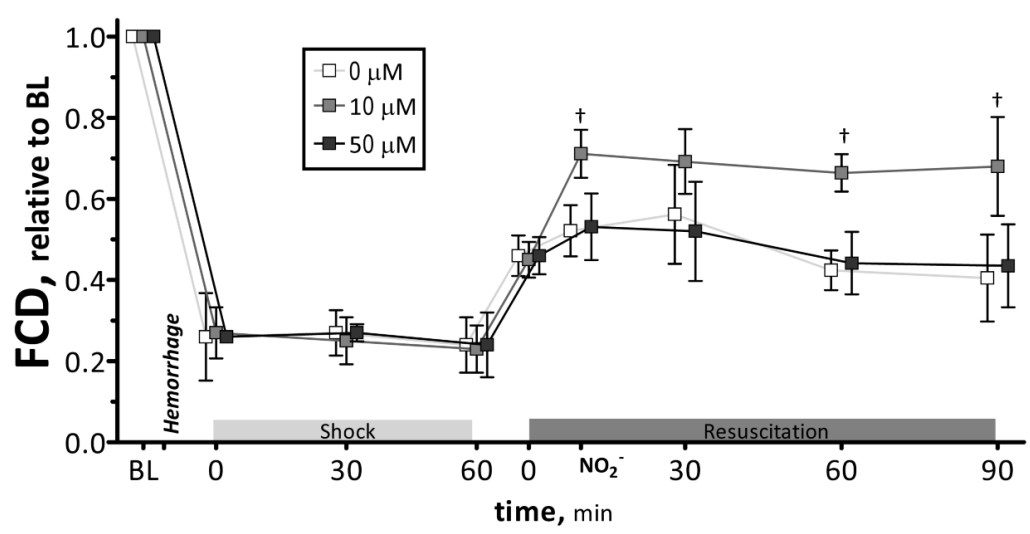

Figure 3.

Changes in functional capillary density (FCD) during hemorrhagic shock resuscitation for all groups. FCD $\left(\mathrm{cm}^{-1}\right)$ at baseline was $0 \mu \mathrm{M}(113 \pm 11) ; 10 \mu \mathrm{M}(102 \pm 10) ; 50 \mu \mathrm{M}(98 \pm 8)$. Broken line represents baseline level. Broken line represents baseline level. Broken line represents baseline level. $\nmid \mathrm{z}, \mathrm{P}<0.05,10 \mu \mathrm{M}$ compared to $0 \mu \mathrm{M}$ and $50 \mu \mathrm{M}$. 


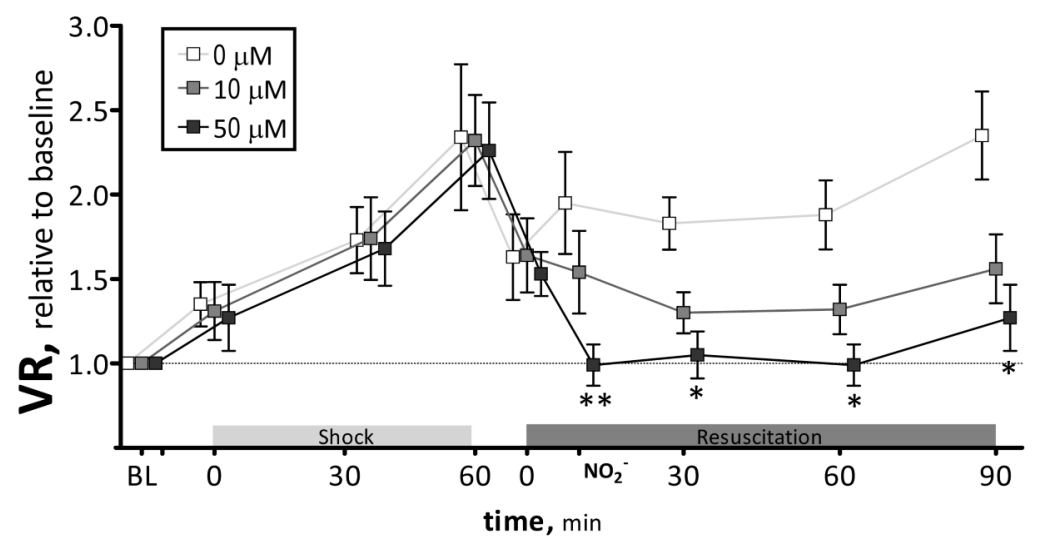

Figure 4.

Calculated vascular resistance (MAP/blood flow) relative to baseline during hemorrhagic shock and resuscitation for all groups. Broken line represents baseline level. **, $\mathrm{P}<0.05$, $50 \mu \mathrm{M}$ compared to $0 \mu \mathrm{M}$ and $0 \mu \mathrm{M} ; *, \mathrm{P}<0.05,50 \mu \mathrm{M}$ compared to $0 \mu \mathrm{M}$. 


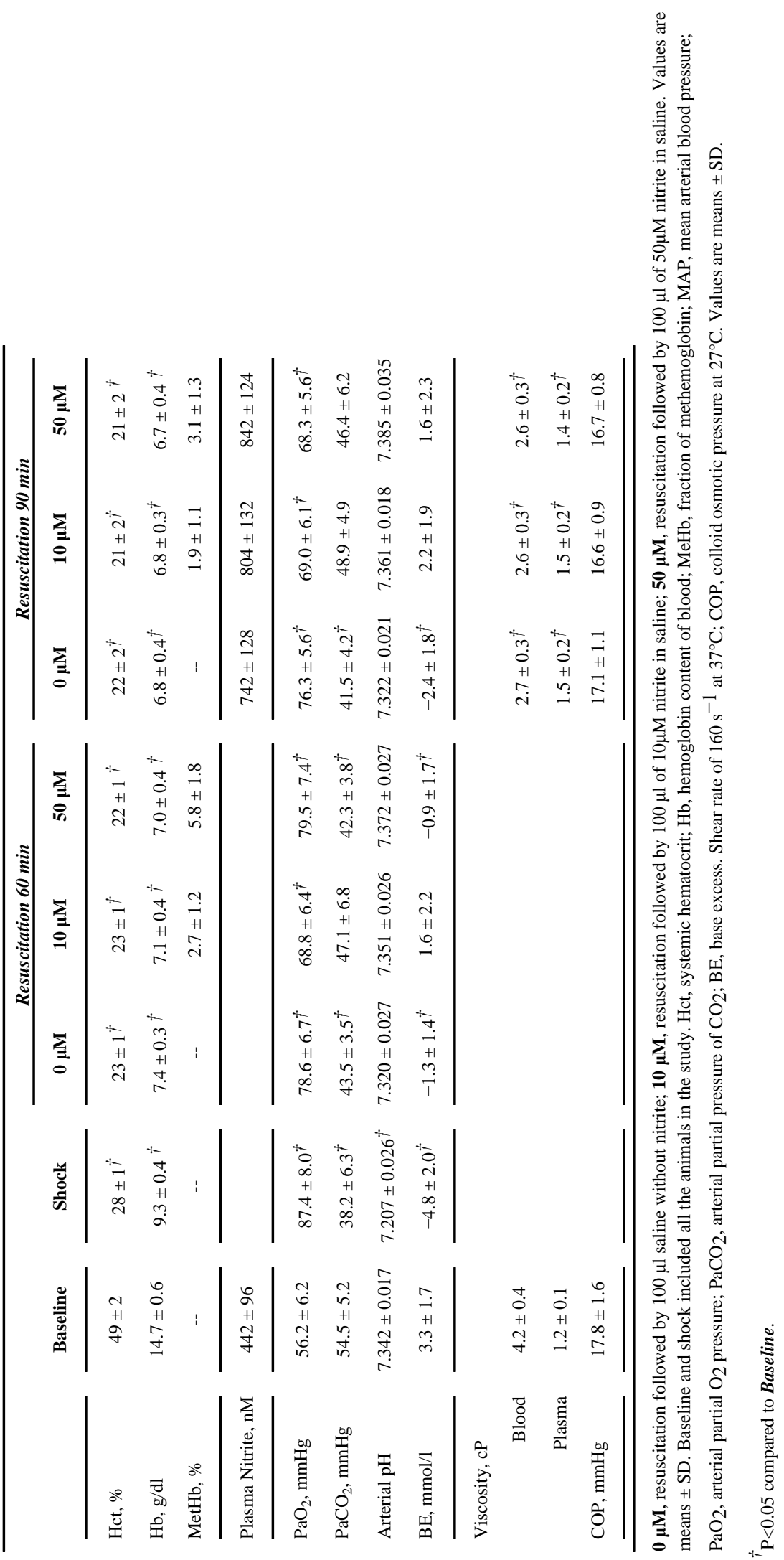

